\title{
PENGALAMAN BELAJAR MAHASISWA TERKAIT PERAN SKENARIO DALAM TUTORIAL
}

\author{
Nindya Aryanty*, Gandes Retno Rahayu**, Efrayim Suryadi** \\ *Fakultas Kedokteran Universitas Jambi, Jambi \\ **Fakultas Kedokteran Universitas Gadjah Mada, Yogyakarta
}

\begin{abstract}
Background: Tutorial in Problem-based Learning is a learning method where faculty prepares a scenario to trigger students learning through small group discussion. In the first meeting of tutorial, a group of students analyze the scenario given by raising and answering questions to explore phenomenon described in the scenario. Unresolved questions then become students' learning issues which are a starting point for their independent learning. Answers gathered during individual learning then being reported and synthesized on the second meeting. The aim of this study is to investigate student learning experience regarding the role of scenario in tutorial.

Method: Reflective writings of 36 medical students about learning experience using PBL collected at the end of first year were analyzed qualitatively through within-case analysis and cross-case analysis. Methods chosen to increase credibility are peer review and verbatim.

Results: Students found that some scenarios stimulated their learning since it increase students' curiosity. Scenarios discussing the latest newe in medicine also attract to students to learn more. However, majority students admitted that some scenarios not providing enough clues to guide student determining learning objectives. Student preferred to discuss and formulate learning objectives by listing the title/topic of lecture scheduled on the same week as related tutorial session. Scenario that found identical to scenario given on the previous academic year also demotivates students to learn deeply. Students admitted learning from their senior notes in preference to learning from other valid resources. In addition, this study found that scenarios that lead students to discuss topic beyond their first-year competencies also disencourage students learning.

Conclusion: Scenario plays an important role in student learning. Therefore, scenario bave to be carefully designed by determining students' prior knowledge, the length of independent learning session needed and learning resources available for students. It is also necessary to always renew the scenario for every academic year and improve its quality, for example by adding visual trigger along with written text.
\end{abstract}

Keywords: learning experience, scenario, tutorial

\section{ABSTRAK}

Latar Belakang: Problem-based Learning yang diterapkan di Fakultas Kedokteran dengan mengedepankan pembelajaran berpusat pada mahasiswa tentu merupakan pengalaman baru bagi mahasiswa tahun pertama yang terbiasa dengan pembelajaran berpusat pada guru selama menempuh pendidikan sekolah menengah. Sejumlah penelitian dari berbagai program pendidikan kedokteran di seluruh dunia menemukan bahwa mahasiswa mengalami kecemasan, kesulitan, dan merasa tertekan pada awal pembelajaran menggunakan PBL. Penelitianpenelitian ini menyimpulkan pentingnya membekali mahasiswa dengan pemahaman komprehensif mengenai PBL dan berbagai keterampilan yang diperlukan agarmahasiswa dapatmelaksanakan PBL secaramaksimal. Keberadaan program konseling untuk membantu mahasiswa mengatasi kecemasan, kesulitan, dan tekanan selama pembelajaran juga perlu diperhatikan. Penelitian ini bertujuan untuk mengetahui bagaimana persepsi mahasiswa tahun pertama FK UGM tentang PBL, bagaimana pengalaman belajar mereka dan apa yang mereka rencanakan untuk dapat lebih ditingkatkan pada pembelajaran selanjutnya.

Korespondensi: nindya_aryanty@yahoo.co.id

Jl. Rajawali I No. 3, Jambi, Indonesia, 36138, Telp +6285266937383 
Metode: 36 tulisan refleksi mahasiswa mengenai pengalaman belajar menggunakan PBL yang dikumpulkan pada awal dan akhir tahun pertama pembelajaran dianalisis secara kualitatif. Upaya pencapaian kredibilitas dilakukan dengan metode triangulasi waktu, diskusi dengan sejawat, analisis kasus negatif, dan penggunaan verbatim. Peran pembimbing penelitian sebagai auditor menjaga derajat kebergantungan dan kepastian penelitian.

Hasil: Mahasiswa lebih memahami PBL sebagai pembelajaran konstruktif dan pembelajaran yang dimotori oleh keinginan diri sendiri. Berbagai variabel ditemukan mempengaruhi pengalaman belajar mahasiswa menggunakan PBL, yaitu perbedaan antara PBL dengan pembelajaran berpusat pada guru yang dialami semasa SMA, efektifitas Blok 1.1 dalam membekali mahasiswa dengan pemahaman yang komprehensif tentang PBL dan berbagai keterampilan belajar, kualitas scenario, peran tutor, interaksi mahasiswa dalam kelompok, pengaturan jadwal akademik, proses belajar mandiri, dan sistem assesmen. Mayoritas mahasiswa berencana untuk lebih meningkatkan keterampilan belajar, terutama keterampilan mencari referensi belajar, komunikasi efektif, dan manajemen waktu agar selanjutnya dapat melaksanakan PBL dengan lebih baik.

Kesimpulan: Perbedaan antara PBL dan sistem pembelajaran semasa SMA yang mengedepankan pembelajaran berpusat pada guru menuntut Fakultas untuk membekali mahasiswa dengan pemahaman komprehensif tentang PBL dan berbagai keterampilan belajar yang diperlukan agar dapat melaksanakan PBL dengan baik. Fakultas juga perlu memperhatikan berbagai variabel yang mempengaruhi pengalaman belajar mahasiswa menggunakan PBL seperti kualitas scenario, peran tutor, interaksi mahasiswa dalam kelompok, pengaturan jadwal akademik, proses belajar mandiri, dan sistem assessmen, serta selanjutnya memikirkan strategi yang dapat dilakukan untuk mengatasi permasalahan yang dihadapi mahasiswa.

Kata kunci: mahasiswa tahun pertama, persepsi, pengalaman belajar, rencana perbaikan

\section{PENDAHULUAN}

Tutorial merupakan inovasi metode pembelajaran dalam dunia pendidikan, khususnya pendidikan kedokteran kesehatan sejak lebih dari empat dekade yang lalu. Tutorial diterapkan sebagai wujud implementasi pembelajaran berdasarkan masalah (Problem-based learning/PBL) yang mengedepankan prinsip pembelajaran yang berpusat pada mahasiswa (studentcentered). Penerapan PBL dengan metode pembelajaran tutorial ini, selangkah demi selangkah, berbagai institusi pendidikan kedokteran-kesehatan mulai meninggalkan strategi pembelajaran yang dahulunya memusatkan pembelajaran mahasiswa kepada dosen (teachercentred) dengan mayoritas metode pembelajaran berupa perkuliahan satu arah (one-way lecture)., ${ }^{1,2}$

Metode tutorial dalam PBL menyajikan pembelajaran secara kontekstual dengan mengedepankan prinsip partisipasi aktif dan mandiri oleh mahasiswa dalam membangun pengetahuan melalui kolaborasi. Diskusi tutorial dilaksanakan dalam kelompok-kelompok kecil yang terdiri dari sejumlahmahasiswa (5-8 orang). Diskusi dipandu oleh seorang tutor dan pada kelompok diberikan sebuah skenario kasus kedokteran untuk didiskusikan bersama. Sesi pertama tutorial dimulai dengan klarifikasi terhadap konsep-konsep atau fakta-fakta baru yang belum dipahami mahasiswa. Mahasiswa kemudian mengajukan berbagai pertanyaan dan menganalisis kasus dengan hipotesis yang berasal dari pengetahuan mereka sebelumnya. Langkah selanjutnya adalah memformulasikan sendiri tujuan belajarnya dan menetapkan sumber pembelajaran apa yang dapat digunakan dalam pencapaian tujuan belajar tadi. Selama 38-72 jam, mahasiswa diberikan kebebasan belajar mandiri untuk dapat mengumpulkan berbagai informasi berkenaan dengan tujuan belajar yang telah mereka sepakati sebelumnya. Pada sesi kedua diskusi tutorial, mahasiswa akan saling mengutarakan informasi-informasi yang telah mereka kumpulkan dari hasil belajar mandiri, selanjutnya mereka diskusikan dan analisis bersama di dalam kelompok. 4,5

Melalui kasus atau skenario yang diberikan dalam tutorial, mahasiswa distimulasi untuk belajar. Barrows ${ }^{5}$ menekankan bahwa skenario yang digunakan haruslah merupakan kasus-kasus klinis yang sering ditemukan dan penting dikuasai dalam praktek kedokteran sesungguhnya. Materi belajar yang distimulasi melalui 
scenario ini dapat meliputi pengetahuan dasar mekanisme kerja tubuh (seperti anatomi, fisiologi, bioseluler); aspek-aspek klinis yang diperlukan untuk memahami kasus (contohnya gejala dan tanda klinik penyakit, pemeriksaan laboratorium, pemeriksaan radiologis); serta aspek-aspek sosial dan komunitas yang perlu diperhatikan oleh seorang dokter dalam penanganan kasus secara adekuat (seperti kesediaan tempat pelayanan kesehatan, tingkat pendidikan dan kondisi sosial-ekonomi pasien). Materi lain yang tidak kalah penting untuk dibahas adalah aspek individu dan profesionalisme seorang dokter yang diperlukan agar dapat menghadapi kasus pasien dengan tepat, termasuk didalamnya bagaimana perasaan dokter dan berbagai isu etika-legal.

Dengan pembelajaran melalui simulasi kasus atau skenario ini, diharapkan ketika mahasiswa selanjutnya mengikuti pembelajaran fase klinik, mahasiswa telah menjadi seorang yang mampu belajar mandiri dari kasuskasus klinik nyata yang ditemui. Mahasiswa akan memandang setiap kasus klinik yang ditemui sebagai kesempatan untuk menilai sejauh mana kekurangan pengetahuan dan keterampilan yang mahasiswa miliki, selanjutnya mencari sumber-sumber pembelajaran untuk mengatasi kekurangan tersebut sehingga proses pembelajaran akan terus-menerus berlanjut. ${ }^{5}$

Penelitian ini bertujuan untuk mengetahui pengalaman belajar mahasiswa terkait peran skenario dalam tutorial.

\section{METODE}

Jenis penelitian yang digunakan dalam penelitian ini adalah penelitian kualitatif dengan rancangan fenomenologi. Penelitian ini dilakukan di Fakultas

Kedokteran Universitas Gadjah Mada dengan populasi penelitian adalah seluruh mahasiswa tahun pertama FK UGM. Sedangkan unit analisis dalam penelitian ini adalah individu mahasiswa. Sampel penelitian ditetapkan dengan cara purposive sampling dengan metode typical case sampling berdasarkan tulisan refleksi mahasiswa Blok 1.1 yang menunjukkan mahasiswa yang bersangkutan kesulitan dalam pembelajaran menggunakan PBL. Sampel penelitian berjumlah 36 mahasiswa tahun akademik 2009/2010, yaitu 23 mahasiswa berasal dari program reguler dan 13 mahasiswa lainnya berasal dari program internasional.

Pada minggu ketiga dan keempat pembelajaran Blok 1.6, tiga puluh enam mahasiswa yang menjadi sampel penelitian diminta untuk menuliskan refleksi mengenai pengalaman belajar selama hampir satu tahun menggunakan panduan metode refleksi Gibb's yang telah dimodifikasi. Satu orang responden berhalangan hadir sehingga total tulisan refleksi yang dikumpulkan

adalah sejumlah 35 tulisan. Data kemudian dianalisis secara kualitatif (within-case analysisdan cross-case analysis). Untuk meningkatkan keabsahan penelitian, peneliti melakukan diskusi dengan teman sejawat (peer review), dan menggunakan lowinference descriptor (verbatim) dalam menyajikan hasil penelitian.

\section{HASIL DAN PEMBAHASAN}

\section{Karakteristik Responden}

Keseluruhan mahasiswa yang terlibat sebagai responden penelitian ini adalah 35 mahasiswa dengan rata-rata usia 17-19 tahun, 22 mahasiswa program reguler dan 13 mahasiswa program internasional. Sejumlah 30 mahasiswa merupakan mahasiswa asal Indonesia yang berasal dari beragam SMU yang tersebar di berbagai daerah/provinsi di Indonesia sedangkan 5 responden lainnya merupakan mahasiswa program internasional yang berasal dari Malaysia dengan asal SMU Kolej Teknologi Timur.

\section{Pengalaman Belajar Mahasiswa Terkait Peran Skenario dalam Tutorial}

Dalam PBL, skenario digunakan untuk menstimulasi dan memotivasi mahasiswa mempelajari materi dengan lebih mendalam (deep approach). Skenario yang selama ini digunakan dalam pembelajaran tutorial, sebagian dirasakan mampu menstimulasi mahasiswa untuk belajar maupun memacu diskusi ( $n=27)$. Namun, sebagian skenario lainnya dirasakan tidak mampu membuat mahasiswa tertarik untuk mempelajari topik-topik yang terkait didalamnya $(\mathrm{n}=11)$. 
Tabel 1. Pernyataan mahasiswa terkait efektifitas skenario dalam menstimulasi belajar

Skenarionya cukup menarik, dan terkadang lebih ke kejadian sehari-hari, jadi membuat mahasiswa tertarik untuk mempelajarinya. . . Ada banyak skenario yang membuat saya enjoy karena saya merasa itu sangat penting untuk dipelajari. . . . Seandainya saya tertarik dengan skenarionya, pasti saya juga akan ingin mencari lebih banyak lagi pengetahuan ketika independent learning(Responden 29I2)

Some scenarios are very interesting and creates curiosity and interest to read further and deeply about a topic or other related topics. ... At times scenario causes me to be curious. At times it makes me feel inferior as I feel I do not have the knowledge but this create the drive for me to equipped myself with that knowledge. It can be a real eyeopenes (Responden 37I2)
Beberapa skenario kurang menarik, kurang menantang keingintahuan saya untuk mencari tahu lebih lanjut. Jadi kadangkala saya merasa ogah-ogahan untuk mencari tahu dan belajar lebih lanjut (Responden 32I2)

. . but some of them [scenarios] sound quite stupid and not related, causing short discussion. Sometimes I feel irritated as some scenarios would sound stupid and are irrelevant to the learning objectives supposed to be achieved. . . If they [scenarios] are not important or irrelevant, I do not spend much time for it [to learn more] (Responden 30I2)
Salah satu alasan mengapa skenario dirasakan tidak membuat mahasiswa tertarik untuk belajar lebih mendalam adalah karena mayoritas skenario yang ditemukan sama dengan skenario yang diberikan pada mahasiswa tahun sebelumnya. Hal ini mengakibatkan mahasiswa cenderung menggunakan catatan senior untuk membahas skenario tersebut $(\mathrm{n}=8)$. Mahasiswa merasa lebih mudah menemukan jawaban pertanyaan LO dari catatan seniornya, dibanding mencari jawaban dengan menggunakan sumber belajar seperti textbook atau yang lainnya.

"Skenarionya sama dengan tahun lalu, mempermudah belajar, tapi juga membuat kita malas karena sudah ada di HSC tahun kemarin."

"Menyenangkan, karena saya lebih mudah belajar dari HSC tahun lalu ataupun dari slide tahun lalu. Jadi banyak waktu untuk praktikum (laporan)" (Responden 12R2).

"... every year the problem is identical, so its very easy to get the general idea from the last year's note" (Responden 26I2).

Meskipun demikian, beberapa mahasiswa mengungkapkan bahwa walaupun skenario sama dengan skenario tahun sebelumnya, mahasiswa tetap merasa terstimulasi untuk mempelajari materi terkait skenario yang diberikan secara lebih mendalam $(n=6)$. Sebagian skenario dianggap menarik karena menyinggung isu-isu kesehatan terbaru yang tidak didapatkan mahasiswa dalam pembelajaran kuliah atau kegiatan akademik lainnya.

"Walaupun skenario "monoton" (sama seperti tahun sebelumnya). Skenario yang diberikan berbobot, kaya ilmu dan pemacu untuk menambah keingintahuan mahasiswa dan memacu untuk lebih cermat dalam mencari referensi". (Responden 18R2).

"[skenario] baik karena juga menyinggung isu-isu terbaru dalam masyarakat yang belum disinggung saat lecture/ kegiatan lain”.(Responden 8R2).

Terlepas dari skenario yang ditemukan sama dengan tahun sebelumnya ataupun tidak, mahasiswa mengungkapkan beberapa kendala dalam belajar terkait skenario yang diberikan.Terkadang mahasiswa menemukan skenario yang dianggap membingungkan $(\mathrm{n}=16)$. Mahasiswa bingung menentukan apa sebenarnya tujuan belajar (LO) yang diharapkan dari skenario tersebut sehingga beberapa mahasiswa memilih untuk menentukan LO berdasarkan judul/ materi kuliah ( $\mathrm{n}=4)$.

"Berdasarkan skenario yang diberikan, kadangkadang sulit untuk mengetahui maksud dan tujuannya, sehingga sering kami harus melihat, contohnya, dalam minggu ini apa sih yang dikuliahkan. Dari lecture-lecture tersebut kami 
membuat pertanyaan-pertanyaan, agar dalam minggu ini kami dapat mencapai learning objective yang diharapkan”. (Responden 14R2).

Skenario juga dianggap membingungkan karena memberikan interpretasi yang keliru pada mahasiswa $(n=4)$ sehingga diskusi dirasa berjalan diluar topik bahasan yang seharusnya.

"Some of the scenarios are confusing. The way it is structured misleads the students, hence causing out-oftopic discussion. . . . Sometimes, the scenario uses too many unfamiliar terms that when read as a whole, may be interpreted in a different context". (Responden 34I2).

LO yang ditetapkan dari analisis skenario dianggap mahasiswa tidak melingkupi seluruh tujuan belajar yang perlu diketahui. Hal ini diantaranya mengakibatkan proses tutorial menjadi terfokus pada pembahasan pada konteks skenario $(n=4)$. Skenario dianggap tidak sesuai dengan $\mathrm{LO}$ yang perlu dicapai pada tema minggu terkait $(n=7)$. Bahkan beberapa mahasiswa mengungkapkan kebingungan akibat LO skenario yang tumpang tindih dengan tema minggu pembelajaran yang lain $(n=2)$.

"Sometimes, the scenario is not always represent the whole thing that needed to be learnt for the whole week". (Responden 25I2)

"Cuma kadang skenarionya terlalu spesifik sehingga fokus diskusi terlalu scenario-oriented. Padahal kita harus belajar secara luas dan tidak harus selalu berpegang pada skenario. Kalo kejadiannya seperti itu, maka tujuan pembelajaran juga kurang tercapai”. (Responden 13R2).

"Terkadang skenario yang satu dengan yang lainnya saling overlap materi (seharusnya week 3 tapi week 1 udah ada)". (Responden 1R2)

Adapula seorang mahasiswa menganggap cakupan LO skenario terlalu mengarahkan mahasiswa pada pembelajaran ilmu klinik yang dirasa belum sesuai untuk pembelajaran mahasiswa tahun pertama.

"Scenarios leads more to clinical when at first year does not concentrate on clinical. Scenarios stimulates wrong learning objectives". (Responden 37I2).

Namun, seorang mahasiswa lainnya berpendapat berbeda. Mayoritas skenario dirasakan telah memiliki tujuan belajar yang jelas dan mampu memberikan panduan yang baik dalam pembelajaran.

"Most of the scenarios are clear and the objectives from the scenario are easy to grasp. I think it does provide a good guideline appropriate for the week". (Responden 26I2).

Kebingungan dan kesulitan yang dihadapi mahasiswa dalam pembahasan skenario harus dapat diidentifikasi oleh tutor sehingga tutor dapat mengarahkan pembelajaran dengan tepat. Namun, penelitian menemukan bahwa sebagian tutor tidak mengarahkan proses diskusi $(n=3)$ sehingga pembahasan materi dirasa tidak sesuai dengan topik yang seharusnya dipelajari atau tutor malah mengarahkan diskusi pada pembahasan topik yang dianggap mahasiswa tidak tepat $(n=4)$. Sebagian lainnya dirasakan mahasiswa tidak bersungguhsungguh dalam memonitor proses diskusi yang terjadi $(n=20)$ sehingga tidak melakukan intervensi yang diperlukan agar diskusi dapat berjalan efektif. Beberapa tutor tidak memberikan stimulasi pada mahasiswa untuk membahas skenario secara lebih mendalam $(n=8)$.

". . .but there are some [tutors] which does not seem to care about the tutorial that is going on at that time. . .I don't really like tutor who are too quiet and act that they doesn't care when they know that the group is lost during tutorial” (Responden 31I2).

". . other tutor make me feel confuse of what to study because they demand us to know more (the expertise field), which I think it's not our field to know (in our $1^{\text {st }}$ year)" (Responden 36I2).

Skenario merupakan variabel penting dalam pembelajaran mahasiswa didalam PBL. Skenario berfungsi memberikan trigger sehingga mahasiswa termotivasi untuk menemukan penjelasan dari berbagai fenomena yang muncul didalamnya serta mencari hubungan diantara fenomena-fenomena tersebut. Keseluruhan proses tersebut diawali dengan mengaktifkan prior knowledge. Proses menganalisis skenario dilanjutkan hingga mahasiswa menemukan kesenjangan antara pengetahuan yang telah dimiliki dan penjelasan fenomena yang belum terselesaikan. Mahasiswa kemudian merumuskan tujuan belajar dengan penuh kesadaran mengenai pentingnya pengetahuan-pengetahuan tadi untuk dipelajari. Ketika melaksanakan pembelajaran mandiri, mahasiswa 
semakin termotivasi dalam belajar karena tujuan belajar telah dirumuskan olehmahasiswa sendiri. Selanjutnya pada sesi kedua tutorial, mahasiswa saling berdiskusi memberikan penjelasan atas berbagai fenomena yang belum terselesaikan pada sesi pertama. Proses sintesis pengetahuan pun terjadi. ${ }^{6}$

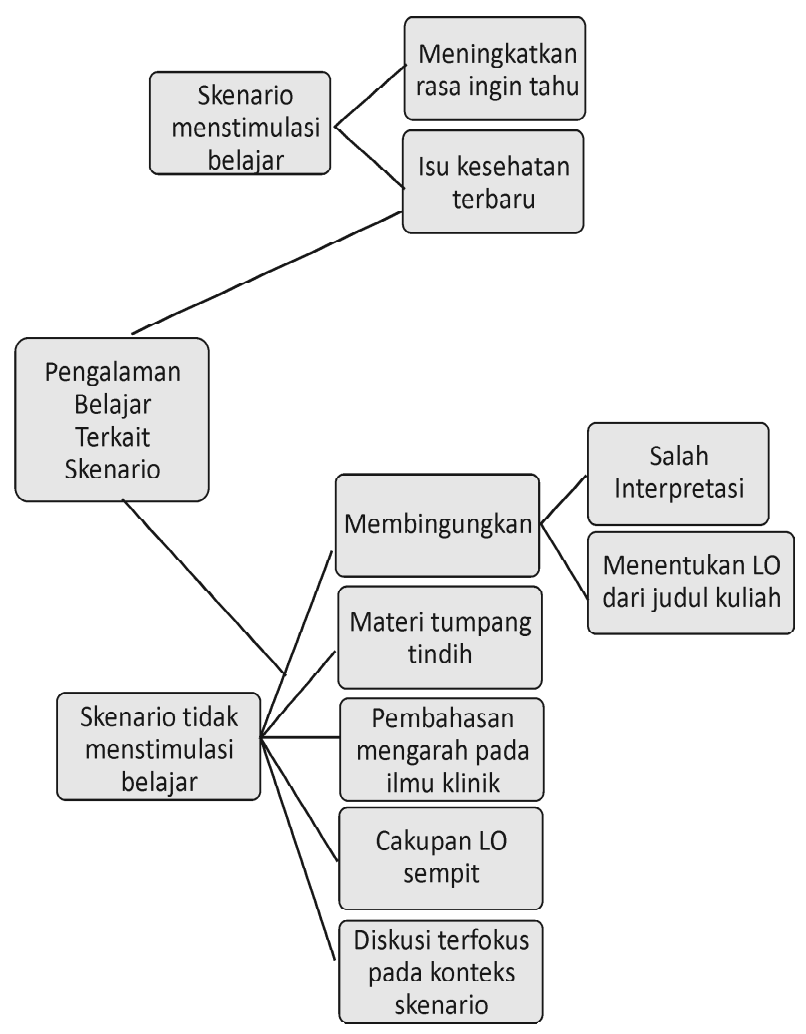

Diagram 1. Pengalaman belajar terkait skenario yang digunakan

Penelitian ini menemukan sebagian skenario dirasakan mahasiswa telah mampu memberikan stimulasi dalam pembelajaran. Namun, mayoritas mahasiswa juga mengungkapkan sebagian skenario lainnya ditemukan membingungkan baik dari segi penggunaan bahasa yang terkadang menyebabkan interpretasi yang beragam diantara mahasiswa maupun menyebabkan mahasiswa kebingungan mengenali apa sebenarnya tujuan belajar yang diharapkan dari skenario yang diberikan.

Salah satu faktor penyebab terjadinya salah interpretasi dan kebingungan dalammenemukenali fenomena yang perlu dikaji lebih lanjut adalah kompleksitas scenario yang diberikan tidak sesuai dengan prior knowledge mahasiswa. Skenario yang terlalu kompleks yang mengharapkan pembahasan berbagai konsep dan materi yang tidak relevan dengan prior knowledge mahasiswa, akanmenyebabkan pembelajaran berjalan tidak efektif. ${ }^{6}$ Ketika mahasiswa tidak memiliki cukup prior knowledge untuk mendiskusikan fenomena-fenomena yang diberikan dalam skenario, maka proses analisis tidak akan berjalan baik.Mahasiswa tidak dapat membangun jaring pengetahuan baru karena prior knowledge yang seharusnya menjadi fondasi bagi pembentukan jarring pengetahuan baru tersebut belum terbentuk. Mahasiswa akan lebih banyak pasif dalam diskusi karena tidak mengerti apa sebenarnya yang harus didiskusikan. Sebagaimana data yang ditemukan dalam hasil analisis mengungkapkan bahwa ketika tutorial dilaksanakan sebelum mahasiswa dijadwalkan mengikuti kuliah terkait topik dalam skenario maka diskusi akan berjalan sangat tidak efektif. Sebaliknya, mahasiswa mengungkapkan ketika kuliah terkait topik skenario diselenggarakan sebelum jadwal tutorial, maka pemahaman hasil belajar mandiri yang diperkuat setelah menerima materi kuliah akan lebih membuat mahasiswa percaya diri dalam menjalankan diskusi.

Kebingungan dalammembahas skenario danmenentukan tujuan belajar yang diharapkan menyebabkan sebagian mahasiswa mengambil jalan pintas dengan membahas skenario dan menentukan tujuan belajar berdasarkan pada judul/materi kuliah yang terjadwal pada minggu/topik yang sama dengan tutorial. Hal ini berarti, proses analisis yang seharusnya terjadi didalam tutorial menjadi tidak berjalan. Mahasiswa tidak membahas skenario dan mengukur sampai dimana penguasaan materi yang telah dimiliki dan merumuskan selanjutnya pengetahuan apa yang perlu dipelajari. Proses yang diharapkan bertujuan untuk mengukur dan menghubungkan prior knowledge dan meningkatkan motivasi belajar karena tujuan belajar dirumuskan sendiri oleh mahasiswa dengan kesadaran bahwa pengetahuan tersebut memang perlu untuk dipahami, menjadi tidak berjalan.

Ditambah lagi kehadiran tutor yang tidak banyak berperan mengarahkan pembelajaran, menyebabkan mahasiswa tetap mengalami kebingungan dan 
mengartikan skenario dengan keliru sehingga tujuan belajar yang dirumuskan pun tidak sesuai dengan yang diharapkan Fakultas. Tutor sebaiknya mampu mengidentifikasi kebingungan yang dialami oleh mahasiswa ini dan diharapkan dapat memberikan intervensi yang cukup dalam mengarahkan mahasiswa untuk menganalisis skenario pada tujuan belajar yang diharapkan. De Grave et al. ${ }^{7}$ merumuskan salah satu peran tutor dalam proses pembelajaran tutorial adalah sebagai diagnostician. Tutor yang dengan cermat mengamati jalannya tutorial akan mampu mendiagnosis proses pembelajaran mahasiswa. Pada sesi pertama diskusi, ketika mahasiswa menganalisis skenario yang diberikan, tutor akan mampu mengidentifikasi sejauh mana prior knowledge yang dimiliki masing-masing mahasiswa, mengidentifikasi pemahaman keliru dari prior knowledge tersebut, serta menemukan kesulitan yang dialami mahasiswa. Pada sesi kedua diskusi, tutor dapat mengobservasi sejauh dan sedalam apa materi telah dikuasai oleh mahasiswa, dan apakah mahasiswa telah mampu mengaplikasikan pemahaman yang ia miliki dengan tepat. Setelah mampu mendiagnosis masingmasing mahasiswa, maka selanjutnya tutor dapat memberikan intervensi yang diperlukan dalam menstimulasi proses pembelajaran.

Disamping kendala pembelajaran yang terjadi akibat kurangnya prior knowledge dan peran tutor yang kurang efektif, kendala lain yang ditemukan dalam penelitian ini yaitu skenario yang identik ataupun berulang dengan tahun pembelajaran sebelumnya. Mahasiswa mengungkapkan adanya kecenderungan untuk mempelajari catatan senior mengenai pembahasan skenario yang identik/ berulang tadi. Sebagian mahasiswa memberi respon positif karena hal ini dianggap mempermudah mahasiswa menemukan sumber belajar dan cukup belajar dengan membaca rangkuman pembahasan skenario dari catatan senior. Dengan demikian, mahasiswa dapat mempersingkat waktu belajar mandiri yang dapat digunakan untuk mengerjakan tugas rumah lainnya seperti tugas praktikum. Sebagian mahasiswa lainnya memberikan respon negatif dengan mengungkapkan bahwa hal ini dirasa menurunkan motivasi dan rasa ingin tahu mereka mempelajari skenario. Mahasiswa menjadi tidak terdorong untuk menganalisis dan mengajukan berbagai pertanyaan yang sungguh ingin digali dari skenario tersebut. Mahasiswa menjadi terpaku pada pertanyaanpertanyaan analisis yang telah dirumuskan seniornya. Mahasiswa dapat menjadi tidak termotivasi untuk mempelajari berbagai literatur karena merasa telah menemukan jawaban dan pemahaman cukup dengan membaca catatan senior.

Beberapa kendala mahasiswa dalam melaksanakan pembelajaran PBL yang ditemukan pada penelitian ini serupa denganyang ditemukan oleh Barman et al. ${ }^{8}$ dalam penelitian cross sectional di Universiti Sains Malaysia. Barman et al. menemukan mahasiswa program Kedokteran Gigi yang juga menjalankan pembelajaran menggunakan PBL, mengungkapkan beberapa skenario sulit untuk didiskusikan, skenario yang berulang juga dirasa menurunkan motivasi mahasiswa dalam mempelajari berbagai referensi untukmenjawablearning issues. Mahasiswa juga menyarankan agar kuliah terkait topik skenario dapat disampaikan sebelum jadwal sesi diskusi tutorial. Penelitian ini memberi masukan bagi institusi untuk mereview dan memperbarui skenario yang digunakan dalam proses tutorial secara reguler.

Dalam rangka menghasilkan skenario yang dapat berperan sebagai trigger bagi pembelajaran mahasiswa, Dolman et al. ${ }^{6}$ memberikan beberapa panduan. Panduan pertama menekankan agar penyusun scenario memperhatikan bagaimana kesesuaian antara scenario dengan prior knowledge mahasiswa. Pembuatan scenario harus dimulai dengan mengukur sejauh mana pemahaman prior knowledge mahasiswa dan mengetahui materi apa saja yang telah ia temukan pada pembelajaran blok-blok sebelumnya. Selanjutnya, barulah dosen menentukan tujuan belajar apa saja yang diharapkan dari pembahasan skenario. Tujuan belajar ini tentu harus sejalan dengan tujuan belajar blok. Skenario perlu memberikan petunjuk (clues) yang dapat mengarahkan diskusi mahasiswa pada perumusan tujuan belajar yang diharapkan ini.

Hal lain yang perlu diperhatikan dalam pembuatan skenario adalah menentukan kompleksitas skenario, yaitu memutuskan konsep-konsep dan materi apa saja yang hendak dibahas dalam skenario dimana pengambilan keputusan ini harus didasarkan pada pemahaman sejauh mana tingkat pengetahuan dan 
keterampilan (skills) telah dimiliki mahasiswa. Ketika diberikan skenario yang terlalu sederhana, mahasiswa akan dengan mudah merumuskan tujuan belajar (learning objective) tanpa didahului proses diskusi yang berarti. Namun, skenario yang terlalu kompleks dan tidak sejalan dengan prior knowledge mahasiswa, akan menghambat diskusi karena mahasiswa mengalami kesulitan dalam menganalisis. Padahal proses diskusi ini sangat penting dalam menentukan nantinya seluas dan sedalam apa mahasiswa perlu mempelajari materi ketika melaksanakan langkah pembelajaran mandiri. Ketika skenario perlu diberikan begitu kompleks karena dianggap sesuai dengan penguasaan prior knowledge, pada mahasiswa tingkat akhir misalnya, maka hal lain yang perlu diperhatikan adalah alokasi waktu yang diberikan untuk mendiskusikan skenario tersebut.

Dosen juga perlu memperhatikan struktur skenario. Skenario yang sangat terstruktur menyebabkan mahasiswa tidak menemukan alasan untuk menyelenggarakan diskusi karena tujuan belajar telah dengan jelas tercantum dalam skenario. Sebaliknya, skenario yang sangat tidak terstruktur akan terlalu menyibukkan mahasiswa pada proses pengelompokkan informasi dan identifikasi masalah apa yang perlu dipelajari. Waktu diskusi malah tidak banyak digunakan untuk proses eksplorasi ide-ide dan penjelasan dari berbagai fenomena yang ditemukan dalam skenario dengan mengaktifkan prior knowledge. Keadaan demikian ditemukan dalam penelitian ini dimana mahasiswa mengungkapkan tidak cukup waktu dalam menjalankan diskusi tutorial, dimana seringkali diskusi pada langkah keempat tutorial tidak terselesaikan.

Saat menyusun skenario, dosen tidak hanya perlu memperhatikan hal-hal terkait skenario seperti yang telah dijelaskan sebelumnya, namun juga memperhitungkan kira-kira berapa lama waktu yang dibutuhkan mahasiswa dalam melaksanakan pembelajaran mandiri dan mempertimbangkan ketersediaan sumber belajar yang diperlukan. Jika materi tutorial terlalu luas untuk dipelajari dalam alokasi waktu belajar mandiri yang ditetapkan, maka hal ini akan menurunkan motivasi belajar mahasiswa. Jika sumber belajar yang diperlukan hanya tersedia sedikit, maka mahasiswa hanya akan menghabiskan sedikit waktu untuk belajar mandiri dari sumber yang tidak terlalu bervariasi. Terlebih lagi ketika mahasiswa menemui kesulitan menemukan sumber belajar yang diperlukan ataupun kesulitan mempelajarinya karena pembahasan dalam sumber belajar tersebut tidak sesuai dengan tingkat pengetahuan yang dimiliki mahasiswa maka kedua hal ini juga dapat menimbulkan tekanan (stressor) bagi mahasiswa dan mengurangi motivasi belajar.

Dalam rangka mempersiapkan skenario yang mampu menstimulasi proses pembelajaran mahasiswa, Azer ${ }^{9}$ mengusulkan penggunaan visual trigger disamping teks tertulis yang biasa digunakan selama ini. Visual trigger yang dimaksud dapat berupa gambar, gambar serial, klip video, kartun, atau bahkan hasil pemeriksaan penunjang pasien (seperti X-foto thoraks, laporan pemeriksaan patologi anatomi, atau hasil analisis urin). Visual trigger digunakan dengan tujuan untuk memberikan tambahan informasi teks skenario sehingga dapat melatih keterampilan mahasiswa mengobservasi pasien (misalnya video yang menampilkan seorang pasien dalam posisi duduk terengah dan menopang tubuh dengan kedua tangan di ruang IGD), menjelaskan konteks tingkat keparahan penyakit (misalnya gambar seorang pasien cedera kepala yang ditempatkan di ICU, gambar seorang pasien gastritis di ruang perawatan), memberikan informasi tambahan tentang lingkungan di sekitar pasien yang perlu menjadi perhatian (misalnya tampak perumahan kumuh pada latar gambar seorang anak penderita gizi buruk, bunyi nafas mengi yang terdengar sebagai latar suara pada video seorang penderita asma), lebih menampilkan gejala dan tanda klinis yang khas (ptosis, spider naevi), serta untuk menampilkan bagaimana keadaan sesungguhnya pasien di dalam skenario sehingga mahasiswa dapat lebih merasakan skenario sebagai pengalaman klinik yang lebih realistik.

\section{KESIMPULAN}

Kualitas skenario yang ditentukan oleh kesesuaian dengan prior knowledge, kompleksitas, dan kejelasan tujuan belajar mempengaruhi peran skenario dalam menstimulasi proses pembelajaran mandiri dan diskusi. Skenario yang berulang dapat menghambat proses pembelajaran. 


\section{SARAN}

Fakultas perlu menyiapkan skenario tutorial secara seksama, yaitu dengan memperhatikan prior knowledge mahasiswa, kompleksitas dan struktur skenario, serta mempertimbangkan ketersediaan waktu belajar mandiri dan sumber belajar yang ada. Skenario juga perlu berisi petunjuk (clues) yang mengarahkan mahasiswa pada tujuan pembelajaran yang diharapkan. Selain itu, skenario yang digunakan di setiap tahun ajaran perlu diperbarui. Fakultas juga dapat meningkatkan kualitas skenario tutorial diantaranya dengan penambahan 'visual trigger', dan selanjutnya dievaluasi keefektifannya terhadap motivasi belajar mahasiswa.

\section{DAFTAR PUSTAKA}

1. Snellen-Balendong H, Dolmans D. Problem-based medical education: block construction. Maastricht: Department of Educational Development and Research Maastricht University; 1999.

2. Dolmans D, De Grave W, Wolfhagen I, Van der Vleuten C. Problem-based learning: future challenges for educational practice and research. Medical Education. 2005;39:732-41.

3. Valle R, Petra I, Martinez-Gonzalez A, Rojaz-Ramirez A, Moralez-Lopez S, Pina-Garza B. Assessment of student performance in problem-based learning tutorial sessions. Medical Education.1999;33:818-22.

4. Savin-Baden M, Major CH. Foundation of problem based learning. London: Open University Press; 2004.

5. Taylor D, Miflin B. Problem-based learning: where are we now? Medical Teacher. 2008;30:742-63.

6. Dolmans D, Snellen-Balendong H. Problem construction. Maastricht: Universitaire Pers Maastricht; 2000.

7. De Grave W, Moust J, Hommes J. The role of the tutor in a problem-based learning curriculum. Maastricht: Universitaire Pers Maastricht; 2003.

8. Barman A, Rogayah J, Ismail N. Problem-based learning as perceived by dental students in University Sains Malaysia. Malaysian Journal of Medical Sciences. 2006; 13(1):63-7.

9. Azer S. Twelve tips for creating trigger images for problem-based learning cases. Medical Teacher. 2007;29;93-7. 